\title{
ANALISA KINERJA BOILER INDUSTRI SETELAH BEROPERASI 24 TAHUN
}

\author{
Sumadi $^{1 *}$, Budi Hartono $^{1}$, Roy Waluyo $^{1}$, Setya Permana Sutisna $^{1}$, Edi Sutoyo $^{1}$ \\ ${ }^{1}$ Fakultas Teknik dan Sains, Universitas Ibn Khaldun Bogor ,Indonesia, 1661
}

\begin{abstract}
ABSTRAK
Pada saat ini banyak boiler dibeberapa industri yang beroperasi dengan tingkat kinerja yang rendah, meskipun kini boiler yang mutakhir mampu beroperasi dengan kinerjanya yang baik sesuai kapasitas rancangannya. Kinerja sebuah boiler bisanya ditandai dengan indikator tingkat penurunan energi panas yang dihasilkan. Salah satu indikatornya adalah efisiensi. Penurunan energi panas sebuah boiler industri dari kapasitas rancangannya maka dikatakan boiler tersebut mengalami penurunan efisiensi. Penurunan efisiensi akan sangat berpengaruh terhadap kualitas produk, disamping itu juga akan meningkatkan biaya produsksi sebagai akibat tingginya pemakaian bahan bakar. Penurunan efisiensi boiler ini disebabkan oleh beberapa hal, diantaranya adalah disebabkan oleh kualitas air pengisi boiler, dan rendahnya kualitas bahan bakar dan kinerja equipment pendukung boiler, seperti fan draft, feed water рump dan lain-lain. Penelitian ini dilakukan dengan tujuan untuk mengetahui faktor penyebab turunnya kinerja boiler setelah beroperasi 24 tahun. Pada penelitian ini telah dilakukan pengecekan kualitas air pengisi dan kualitas bahan bakar yang digunakan serta quipment boiler seperti ( fan draft, feed water pump, system pembakaran). Dari data dan hasil analisa, ditemukan penyebab turunnya kinerja boiler adalah buruknya kualitas air pengisi, rendahnya kualitas bahan bakar yang digunakan, serta turunnya kinerja equipment boiler seperti fan draft, feed water pump, sistem pembakaran, serta sumberdaya manusia.
\end{abstract}

Kata kunci : boiler; kinerja; effisiensi; industri; kualitas; peralatan

\begin{abstract}
At this time many boilers in several industries operate with low performance levels, although now the latest boilers are able to operate with good performance according to their design capacity. The performance of a boiler is usually characterized by an indicator of the level of decline in heat energy produced, this indicator is called efficiency, a decrease in the heat energy of an industrial boiler from its design capacity, it is said that the boiler has decreased efficiency, a decrease in efficiency will greatly affect product quality, besides will increase production costs as a result of high fuel consumption. This decrease in boiler efficiency is caused by several things, including the quality of boiler feed water, and the low quality of fuel and the performance of boiler support equipment, such as fan draft, feed water pump and others. This research was conducted with the aim of knowing the factors causing the decline in boiler performance to $9.85 \%$ after operating for 24 years. In this study, the quality of feed water and the quality of the fuel used, and boiler equipment such as (fan draft, feed water pump, combustion system) and the quality of human resources were checked. From the data and analysis results, the causes of the decline in boiler performance are poor quality of feed water, low quality of the fuel used, and decreased performance of boiler equipment, such as fan draft, feed water pump, combustion system, fuel quality, and human resources.
\end{abstract}

Keywords: boiler; performance; efficiency; industry; quality; equipment

\footnotetext{
* Koresponden

e-mail: sumadi@ft.uika-bogor.ac.id
}

Diterima 09 Februari 2021; Penerimaan hasil revisi 21 Juli 2021; Disetujui 05 Agustus 2021

Tersedia online September 2021

AME (Aplikasi Mekanika dan Energi): Jurnal Ilmiah Teknik Mesin @ 2021 


\section{PENDAHULUAN}

Ditengah persaingan antar industri yang sangat ketat saat ini, baik ditingkat nasional maupun ditingkat regional dan international terlebih ada perdagangan bebas ditingkat regional ASEAN saat ini yang disebut dengan ASEAN free Trade Area atau disingkat dengan AFTA, dimana industri nasional dihadapkan pada tantangan global, baik dari ASEAN maupun dari Eropa, hal ini menutut industri Nasional harus menyiapkan diri gunakan menghadapi tantangan tersebut, untuk tercapainya hal ini maka , industri nasional harus mampu meningkatkan kualitas produk maupun jasa yang dihasilkan, disisi lain menurunnya daya beli masyarakat terus menurun merupakan tantangan yang sangat berat bagi industri untuk bisa bertahan (survive). Salah satu cara yang sangat ampuh adalah dengan meningkat kualitas sumber daya,baik kualitas SDM dan kualitas Aset untuk pendukung produski, serta didukung dengan manajemen yang berkualitas, sehingga diharapkan produk yang dihasilkan akan menjadi lebih berkualitas, harga kompetitif, dan delivery time yang terukur. Merupakan jawaban yang tepat dalam berbisnis dalam kondisi seperti ini.

Boiler merupakan salah satu asep pendukung proses produksi yang sangat penting dalam industr manufaktur, sala satu type boiler yang dikaji adalah seperti terlihat pada gambar 1 dibawah :

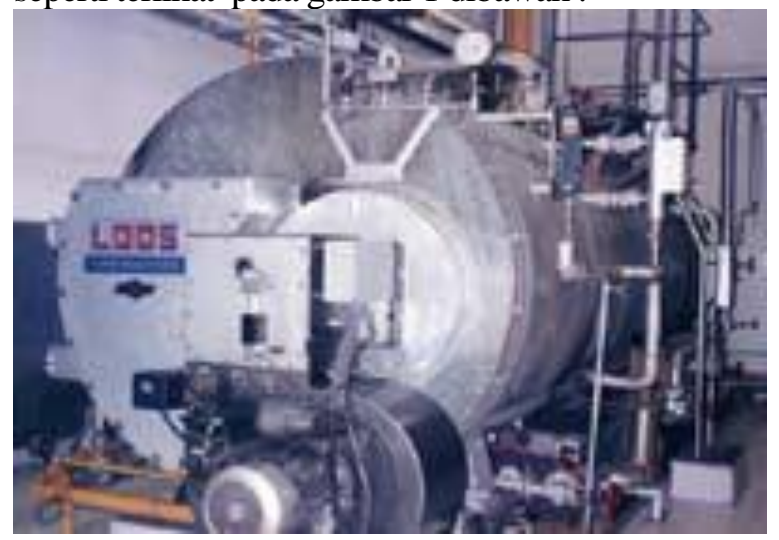

Gambar 1. Fire Tube Boiler

Data Design Fire Tube Boiler

$\begin{array}{lll}\text { Merk } & =\text { Clever brook } \\ \text { Seri } & & =\text { No L } 43723 \\ \text { Tahun } & & =1972 \\ \text { Output } & & =48.000 \mathrm{Kg} / \mathrm{hr} \\ \text { Design pressure } & & =16 \mathrm{bar} \\ \text { Max working preasure } & & =18 \mathrm{bar} \\ \text { Bahan bakar } & & =\mathrm{HSD}\end{array}$

Banyak para engineer dan peneliti telah mengkaji kinerja boiler ini, mengingat boiler merupakan alat yang sangat vital dalam industri manufaktur, diantaranya :
Christian Tallu Karaeng, Iswandi, Firman, Muh.Nuzul,(2013);Analisa Kinerja Boiler Pada PLTU Unit 1 PT.SEMEN TONASA, pada penelitian merekan menimpulkan kehilangan panas terbesar disebabkan oleh gas buang kering.dimana pada operasi tahun 2004, 5,59 $\%$ pada tahun 2013 menjadi 5,79\%.[1]

Aditio Primayudi, Aji Nugroho (2015); Analisa Kehilangan Energi Pada Fire Tube Boiler Kapasitas 10 Ton, mereka menyimpulkan bahwa penyebab turunnya effisiensi sebesar 16,68\% disebabkan oleh pengaturan sistem kontrol bahan bakar yang tidak optimal.[2]

Hendri,Suhengki,Panji Ramadhan (2017) : Analisa Effisiensi Boiler Dengan Metode Heat Loss Sebelum dan Sesudah Overhaul PT.Indonesia Power UBP PLTU Lontar Unit 3, Pada penelitian ini mereka berpendapat 3 hal penyebab kehilangan panas pada boiler adalah, Gas buang kering, kehilangan Panas Moistur Bahan bakar dan kehilangan panas karena pembakaran hidrogen.[3]

Alfi Astra Ryanda (2018); Analisis Effisiensi Paket Boiler 34-6007-U Pada Pabrik P-IB. PT. Pupuk Sriwidjaja Palembang. Pada penelitian ini mereka berkesimpulan bahwa penyebab penurunan effisiensi boiler adalah Bahan bakar[4].

Singgih Hidayanto,(2016);Analisis Performa Water Tube Boiler Kapasitas 115 Ton /Jam Di PT.PERTAMINA REFINERY UNIT VI Balongan Indramayu, pada penelitian ini menyimpulkan penurunan bahwa penurunan effisiensi boiler disebabkan oleh kehilangan panas radiasi.[5]

Asmudi, ; Analisa Unjuk Kerja Boiler Terhadap Terhadap Penurunan Daya Pada PLTU. PT. Indonesia Power UBP Perak, pada penelitian ini menimpulkan penurunan daya disebabkan oleh adanya pengotoran dari bahan bakar dan Air umpan.[6]

Dari penelitian diatas dapat disimpulkan bawa penyebab penurunan effisiensi boiler di pengaruhi oleh,Gas buang, sistem kontrol bahan bakar,moisture bahan bakar, hidrogen, kehilangan panas radiasi dan pengotoran.

Pada penelitian yang saya lakukan dan berdasarkan pengalaman selama 20 tahun pada pemeliharaan boiler disalah satu perusahaan industri kertas, beberapa faktor utama penyebab penurunan effisiensi bolier adalah Air pengisi boiler dengan $\mathrm{pH}$ yang tinggi (basa) bisa menebabkan terjadinya endapan lumpur pada tube boiler, faktor kedua adalah qualitas bahan bakar terutama bila menggunakan bahan HSD dimana kadar air (Moisture) yang sangat tinggi, hal ini akan menyebabkan pembakaran menjadi tidak sempurna,faktor ketiga adalah Make up water ( air panas return / recyling) yang digunakan pada sebagai air tambah pada feed water tank untuk menaikkan temperatur air pengisi/ umpan, faktor ke empat adalah kinerja dari equipmen pendukung dari boiler seperti feed water pump, Fan, sand filter air 
pengisi,sistem control burner dll, penurunan kinerja equipment akan sangat berpengaruh terhadap kinerja boiler, oleh karena itu untuk menjaganya perlu dilakukan penerapan metode pemeliharaan yang tepat seperti penerapan metode Reliability Centre Maintenance sangat diperlukan dan dilakukan secara konsisten, tentunya perlu didukung oleh SDM yang handal, Keuangan yang optimal.

\section{METODE PENELITIAN}

Dalam penelitian ini dilakukan kajian sebagai berikut dilakukan langkah-langkah sebagai berikut sesuai diagram alir pada gambar 1 .

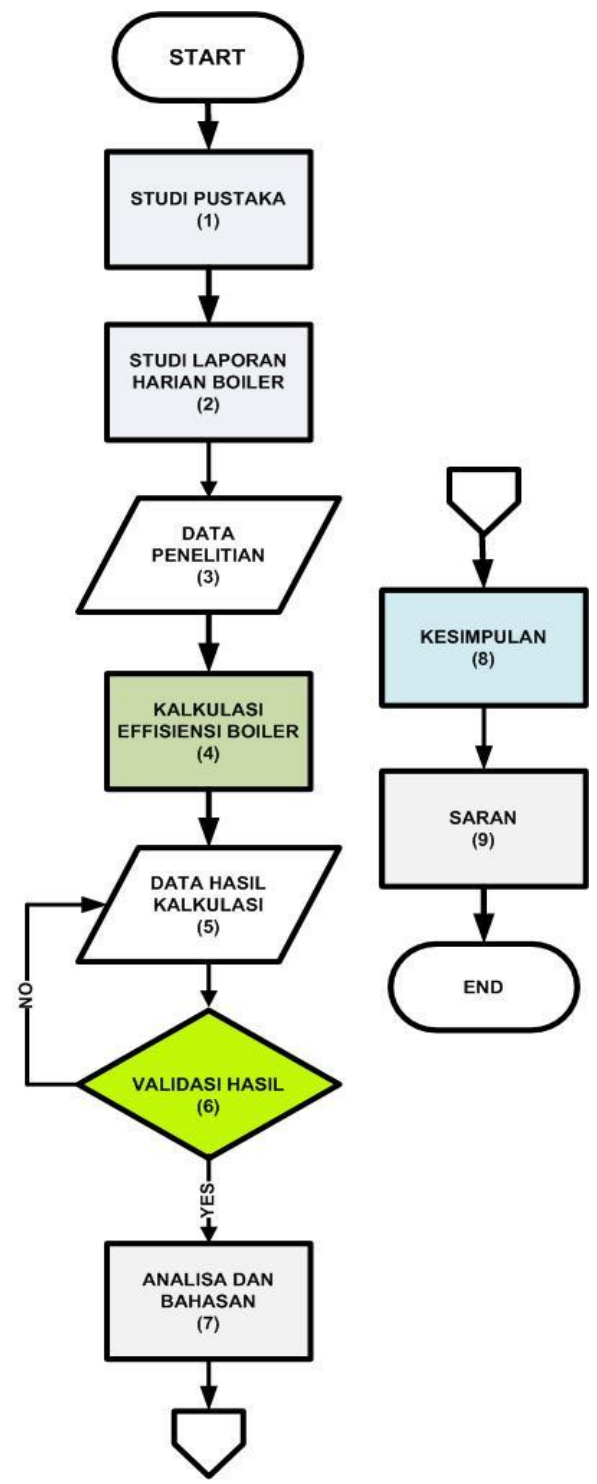

Gambar 1: Diagram Alir Penelitian

Diagram alir dapat dijelaskan sebagai berikut :

Langkah pertama adalah melakukan studi pustaka terkait fokus penelitian tentang boiler. Pada langkah ini dilakukan kajian khusus pada refrensi secara umum termasuk standard effisiensi boiler

Langkah kedua melakukan kajian terhadap laporan segala aktivitas yang dilakukan terhadap pengoperasian boiler, laporan air pengisi boiler, laporan aktivitas pemeliharaan yang dilakukan pengoperasian boiler, termasuk kegiatan preventive, breakdown, dan overhaul, dilakukan juga kajian terhadap laporan qualitas bahan bakar, proses penerimaan bahan bakar dan Standard Operating procedure pengoperasian boiler.

Langkah ketiga adalah pengumpulan data -data yang didapat berdasarkan studi pustaka, dan kajian laporan aktivitas laporan harian pengoperasian boiler termasuk data qualitas air pengisi, data kegiatan maintenance, dan data qualitas bahan bakar dalam hal ini HSD (High Speed Diesel). Langkah ke empat adalah melakukan kalkulasi effisiensy boiler. Langkah kelima adalah mengumpulkan data hasil kalkukalsi effisiensi boiler. Langkah keenam adalah melakukan validasi antara hasil kalkulasi effisiency boiler dengan effisienscy boiler sesuai design pabrikan kalau hasilnya tidak sesuai maka hasil yang didapat akan dilakukan kalkulasi ulang dan apabila hasil kalkulasi eefisiensi boiler sesuai maka akan dilanjutkan dengan bahasan dan kesimpulan. Langkah ke ke tujuh adalah melakukan bahasan terhadap hasil perhitungan effisiency yang didapat dengan faktor-faktor penyebab turunnya kinerja boiler antara lain faktor qualitas air pengisi, faktor kegiatan tindakan preventive, breakdoewn dan overhaule, faktor qualitas bahan bakar dan faktor prosedure pengoperasian boiler. Langkah ke delapan adalah membuat kesimpulan akhir dari kajian penelitian. Langkah ke sembilan adalah membuat saran-saran yang harus dilakukan untuk menjaga kinerja boiler tetap sesuai dengan design hal ini penting agar pihak manajemen mengetahui akar penyebab turunnya kinerja boiler, sehingga pihak manajemen bisa mengantisipasi kerusakan yang disebabkan oleh kesalah serupa sehinggan tidak berulangan, tentunya kita tambhakan berdasarkan pengalaman - yang pernah didapat selama bekerja dilapangan.termasuk disarankan agar operator boiler selalu dilakukan trainning keahlian yang bersertifikat dengan kategori operator boiler kelas 1 .

\section{Data Desain Boiler}

$\begin{array}{lc}\text { Steam Cons } & =295.340 \mathrm{Lbs} \\ \text { h1 }(\text { Enthalpi Steam) } & =1200.2 \mathrm{BTU} \\ \text { h2 }(\text { Enthalpy Feed water) } & =180.6 \mathrm{BTU} \\ \text { h3 (Blowdown water) } & =368.46 \mathrm{BTU} \\ \text { HHV NG (High HeatingValue) } & =1010.459 \mathrm{BTU} \\ \text { Natural Oil } & =347.280 \mathrm{ft} 3 \\ \text { Ido } & =10600 \mathrm{Ltr} \\ \text { Feed Water Ride } & =306.306 \mathrm{Lbs} \\ \text { Blowdown } & =10.876 \mathrm{Lbs} \\ \text { Effisiensi Boiler } & =81.45 \%\end{array}$


Goal Effisiensi Boiler

$=80.00 \%$

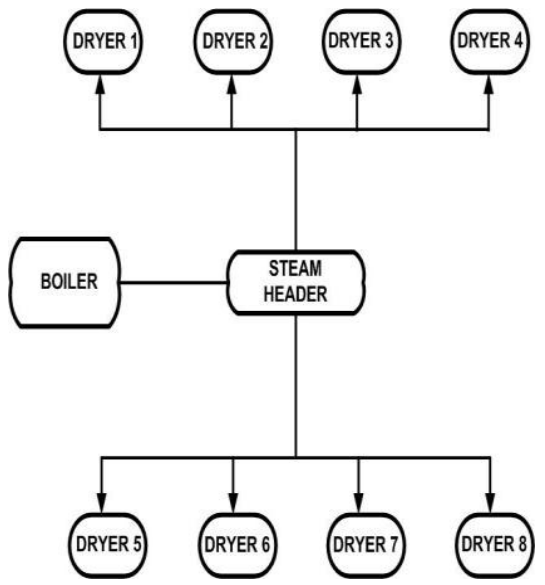

Gambar 2. Diagram Alir Distribusi Steam

Di lihat dari diagram alir distribusi boiler ini bahwa terlihat steam yang dihasilkan boiler di distribusikan ke bebebarapa cluster dryer dalam melakukan pengeringan produk

\section{STANDARD LAPORAN HARIAN BOILER}

Dalam melakukan penelitian ini di dapat standar kualitas air pengisi boiler, seperti terlihat dalam Tabel 1 dibawah:

Tabel 1 Standard Laporan Harian Boiler

\begin{tabular}{|c|c|c|c|c|c|c|c|c|c|c|c|c|c|c|c|c|c|c|}
\hline \multicolumn{19}{|c|}{ LAPORAN HARIAN BOILER } \\
\hline & & & \multicolumn{14}{|c|}{ JAM } & & \\
\hline & & & Standized & 8.00 & 10.02 & 012 & 201 & 14000 & 16,00 & 28.00 & 20.00 & 0 & $0 \mid 24000$ & $0 \mid 0200$ & 04.00 & 06,10 & & \\
\hline \multirow{3}{*}{ 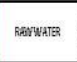 } & pint & & $65.7,75$ & 6.4 & 6.3 & 6.4 & & 64 & & 6.4 & 5.4 & 6.4 & 5.4 & & 6.4 & & & \\
\hline & Harthes & Practats & 3] $13 \sin x \mid$ & 6 & & 6: & 64 & 63 & 64 & & & 64 & & & 626.4 & 6.4 & & \\
\hline & Cenductivity & & & & & & & & & & & & & & & & & \\
\hline \multirow{2}{*}{ AESOF } & Hardness & PPancace & 23 0 & & & & & & & & & & & & & & & \\
\hline & CL & PPMCacos & 3 amax & 20 & 20 & & 20 & 20 & 20 & 20 & 20 & 20 & 20 & 20 & 20 & 20 & & \\
\hline \multirow{4}{*}{ 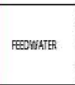 } & 배 & & $755.8,5$ & 7,5 & 7,6 & & 7, & 7,6 & 7,6 & 7,6 & 0,6 & 7,5 & 7,6 & 7,6 & 7,7 & 7,5 & & \\
\hline & $\begin{array}{l}\text { Hexdouss } \\
\end{array}$ & PPMCOC & 83 0 & & & & & & & & & & & & & & & \\
\hline & & PrMGact & 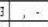 & & & & & & & & & & & & & & & \\
\hline & Cenducitity & & & & & & & & & & & & & & & & & \\
\hline \multirow{6}{*}{ PalFwher } & 매 & & $11,5 \cdot-1,5$ & 10 & 10 & & 10 & 9 & 10 & 11 & 10 & 11 & 10,5 & 10 & 10 & 10,5 & & \\
\hline & Harthess & Ppuscace & & & & & & & & & & & & & & & & \\
\hline & 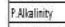 & Prucaco & $13701 \mathrm{max}$ & 300 & 695 & & mo & mo & mo & No & no & 690 & 695 & 695 & no & 700 & & \\
\hline & Mo. Malintsy & PPMGace & 3) Bearti & & & & & & & & & & & & & & & \\
\hline & $\mathrm{GL}$ & $\begin{array}{c}\text { PPMKac } \\
\end{array}$ & $48 \mid$ max & 39 & 39 & & 40 & 40 & 39 & 39 & 39 & 40 & 39 & 39 & 40 & 39 & & \\
\hline & Candocinity & & $30 / \operatorname{lnax}$ & & & & & & & & & & & & & & & \\
\hline \multirow{3}{*}{ 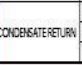 } & phi & & $7,5 \cdot-8,0$ & 7,6 & 7,5 & & 7,6 & 7,5 & 7,6 & 7,5 & 7,5 & 7,6 & 7,9 & 78 & 7,9 & 78 & & \\
\hline & 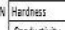 & PPMGaC & 3. 0 & & & & & & & & & & & & & & & \\
\hline & consulutions & & $\begin{array}{ll}8 & 0 \\
8\end{array}$ & & & & & & & & & & & & & & & \\
\hline
\end{tabular}

Pada tabel terlihat standar $\mathrm{pH}$ raw water adalah 6,57,5, Hardness 6,5 max, pada feed water boiler didapat standar $\mathrm{pH}$ adalah 7,5 - 8,5 sedang hadnessnya 0 , untuk boiler water $\mathrm{pH}$ adalah 10,5 - 11,5. Untuk P.Alkalinity adalah PPM CaCo3 max 700, C.L adalah 40 max, untuk conductivity US adalah 300 max.

Untuk Condensate return pH max adalah 7,5 - 8,5.

\section{Perhitungan Efisiensi Boiler}

Konsumsi boiler h1 (Entalphi steam) table fixed

$=1200.2 \mathrm{BTU}$

h2 (Entalphi Feed Water) table

$=180.6 \mathrm{BTU}$

h3 (Blowdown Water) Table Fixed $=368.46$ BTU

HHV NG (High Heating Value) $\quad=1010.459$

Natural Oil

$=347.280 \mathrm{ft} 3$

Ido

Feed Water Ride

$=10200 \mathrm{Ltr}$

Blowdown

Efisiensi Boiler

$=292.746 \mathrm{Lbs}$

$=9.694 \mathrm{Lbs}$

$=71.06 \%$

$=80 \%$

Goal Efisiensi Boiler

- Bahan bakar menggunakan High Flow Oil (HFO) = $\mathrm{NHV}=46.342 \mathrm{kj} / \mathrm{kg}$

$\begin{array}{ll}\operatorname{Karbon}(\mathrm{C}) & =61.34 \% \\ \operatorname{Hydrogen}(\mathrm{H}) & =13.25 \% \\ \mathrm{~S} & =1.1 \% \\ \text { Abu (Ash) } & =1.8 \%\end{array}$

Fuel Moisture (Embun pada bahan bakar) $=1 \%$

Dry Fuel (Bahan Bakar Pengeringan) $=99 \%$

Temperature $(\mathrm{T}) \quad=105 \%$

- Udara pembakaran (Udara Kering)

Dry air (udara kering) $\quad=21.14 \% \mathrm{O}_{2}$

Temperature $(\mathrm{T}) \quad=72.84 \% \mathrm{~N}_{2}$

Moisture (embun) $\quad=0.011 \frac{\mathrm{Kg} \mathrm{H}_{2} \mathrm{O}}{\mathrm{Kg} \text { Dry Air }}$

Temperature $(\mathrm{T}) \quad=27 \%$

- $\quad$ Flue gas (Cerobong asap) komposisi $=7.2625 \%$

Temperature $(\mathrm{T}) \quad=325^{\circ} \mathrm{C}$

- $\operatorname{Residu}(\mathrm{Abu}) \quad=100 \%$ Ash

- $\quad$ Feed Water (Maximum Air) $=100 \% \mathrm{H}_{2} \mathrm{O}=14601$

$\mathrm{Kj} / \mathrm{Kg}$

Temperature $(\mathrm{T}) \quad=64.135 \%$

- $\operatorname{Steam}(\mathrm{Uap})=100 \% \mathrm{H}_{2} \mathrm{O}=2.763 \mathrm{Kj} / \mathrm{Kg}$

Temperature $(\mathrm{T}) \quad=149.26$

\section{DATA PERHITUNGAN NERACA ENERGI}

Tabel 2 Data Perhitungan Neraca Energi

\begin{tabular}{|c|l|c|c|c|}
\hline \multicolumn{5}{|c|}{ DATA PERHITUNGAN KINERA BOILR } \\
\hline No & \multicolumn{1}{|c|}{ NAM/ Jam } & $\mathrm{Kj} / \mathrm{Kg}$ & $\%$ \\
\hline B & NERACA ENERGI & & & \\
\hline 1 & Panas Sensible (masuk) dari BB (HF) & & 199 & \\
\hline 2 & Panas Sensible udara kering (HDA) & & 1,34 & \\
\hline 3 & Panas Sensible kadar air dalam udara Pemb (HYA) & & 2,44 & \\
\hline 4 & Panas Sensible Udara pembakaran (HA) & & 71,1 & \\
\hline 5 & Panas sensible Residu (HR) & & 41,2 & \\
\hline 6 & Panas Sensible Flue Gas (HG) & & 1805 & \\
\hline C & Total Energi Input & $25.246,87$ & & \\
\hline D & Total Energi Loses & 7156,04 & & \\
\hline E & Effisiensi & & & 71,6 \\
\hline
\end{tabular}


Tabel 3 Data Perhitungan Neraca Masa

DATA PERHITUNGAN KINERJA BOILER

\begin{tabular}{|r|l|r|r|r|r|}
\hline No & \multicolumn{1}{|c|}{ NAMA } & $\mathrm{Kg} / \mathrm{Jam}$ & $\mathrm{Kj} / \mathrm{Kg}$ & & 96 \\
\hline A & NERACA MASA & & & & \\
\hline 1 & Kadar Air Dalam Bahan Bakar & 0,1 & & & \\
\hline 2 & Kebutuhan Udara Kering & & & & \\
\hline & SA & & 3,24 & & \\
\hline 3 & Excess Air (udara berlebih) & & & & 22 \\
\hline & CO2 & & & 51,1 & \\
\hline & SO2 & & & 33 & \\
\hline & $\mathrm{O}_{2}$ & & & 21,4 & \\
\hline & N2 & & & 84,4 & \\
\hline 4 & Komposisi O2 dalam dry flue gas & & & & 7,26 \\
\hline 5 & Kebutuhan Udara Kering sebenarnya & & 3,96 & & \\
\hline 6 & Kadar air Dalam udara pembakaran & & 0,04 & & \\
\hline 7 & Total Masa Output & 5,01 & & & \\
\hline 8 & Masa residu & 0,018 & & & \\
\hline 9 & Flue gas (asap Cerobong) & & & & \\
\hline & CO2 & 22,48 & & & \\
\hline & H2O & 0,521 & & & \\
\hline & SO & 0,22 & & & \\
\hline & O & 0,15 & & & \\
\hline & N 2 & 2,88 & & & \\
\hline 10 & Total Masa Output & 26,26 & & & \\
\hline
\end{tabular}

\section{ANALISA DAN BAHASAN}

Dari hasil perhitungan efisiensi boiler didapat adalah $71,6 \%$, hal ini mengalami penurunan kalau dilihat sejak di instal pada tahun 23 tahun atau setara 201480 jam operasi, design effisiensi boiler adalah sebessar $81,4 \%$ dimana mengalami penurunan sebesar 9,8\% atau rata-rata penurunan $0,426 \%$ pertahun .

Berdasarkan pengalaman boiler akan mengalami penurunan kinerja disebabkan oleh beberapa faktor antara lain:

1.Kualitas bahan bakar (effect of fuel) yang buruk, seperti kadar air (moisture Content) yang tinggi, dan komposisi seperti hydrogen dan lainnya.

2.Kualitas air pengisi boiler yang buruk seperti $\mathrm{PH}$ air yang rendah, hal ini bisa menyebabkan terjadinya pengotoran pipa /tube boiler hal ini akan menyebabkan proses perpindahan panas akan menjadi lebih lama.

3.Turunnya kinerja komponen pendukung boiler alat pembakar seperti Burner yang tidak membakar dengan sempurna,seperti sistem kontrol burner yang tidak stabil

4.Temperatur make up water yang rendah, hal ini akan menyebabkan temperatur air pengisi di feed water tank rendah sehingga membutuhkan banyak energi dalam proses pembakaran.
5.Kinerja feed water pump yang buruk, seperti putaran pompa menjadi tidak maksimal, seperti kopeling yang rusak, tidak aligment, hal ini akan mempengaruhi kurangnya supply air pengisi yang masuk ke boiler menjadi tidak maksimal.

6.Faktor kelebihan udara (Excess Air), pembakaran didalam sistem boiler selalu membutuhkan udara lebih dengan maksud untuk mencapai pembakaran sempurna.

7.Beban boiler (Firing Rate). Beban boiler yang berada dalam range efisiensi terbaik atau tertinggi adalah $70 \%$ - 90\%dari beban maksimum

8. Temperatur Flue Gas. Tingginya temperatur flue gas mengisyaratkan tingginya panas yang dibawa oleh flue gas, jelas ini merupakan suatu kerugian.

9.Blow down water adalah bisa menjadi salah satu faktor yang besar pengaruhnya terhadap efisiensi boiler. panas yang terbawah keluar oleh air blow down merupakan suatu kerugian.

10.Power supply ke sistem boiler yang tidak stabil. Power house / Generator set yang tidak siap operasi dan tidak handal / realiability.

11.Kualitas sumber daya manusia yang tidak disiplin dalam melakukan monitor terhadap kondisi boiler saat beroperasi.

\section{KESIMPULAN}

Dari hasil bahasan di atas dapat disimpulkan bahwa, penurunan kinerja boiler di sebabkan oleh, kualitas bahan bakar yang buruk, kualitas air pengisi boiler yang jelek, turunnya kinerja burner boiler, rendahnya temperatur make up water, rendahnya kinerja komponen pendukung boiler seperti feed water pump, kualitas sdm yang rendah dan power supply yang tidak stabil

\section{SARAN}

Agar kinerja boiler menjadi lebih baik disaran sebagai berikut :

1.Buat standar operating prosedur (SOP) dalam pengoperasian boiler

2.Tingkatkan kualitas SDM / upgrade kualitas SDM

3.Jaga Kualitas bahan bakar, air pengisi boiler,dan kualitas komponen pendukung operasional boiler.

4.Jaga Kualitas maker up water, untuk penghematan bahan bakar. 


\section{DAFTAR PUSTAKA}

[1] Christian Tallu Karaeng, Iswandi, Firman, Muh.Nuzul,(2013);Analisa Kinerja Boiler Pada PLTU Unit 1 PT.SEMEN TONASA.

[2] Aditio Primayudi, Aji Nugroho (2015); Analisa Kehilangan Energi Pada Fire Tube Boiler Kapasitas 10 Ton.

[3] Hendri,Suhengki,Panji Ramadhan (2017) : Analisa Effisiensi Boiler Dengan Metode Heat Loss Sebelum dan Sesudah Overhaul PT.Indonesia Power UBP PLTU Lontar Unit 3.

[4] Alfi Astra Ryanda (2018); Analisis Effisiensi Paket Boiler 34-6007-U Pada Pabrik P-IB. PT. Pupuk Sriwidjaja Palembang.

[5] Singgih Hidayanto,(2016);Analisis Performa Water Tube Boiler Kapasitas 115 Ton /Jam Di PT.PERTAMINA REFINERY UNIT VI Balongan Indramayu.

[6] Asmudi, ; Analisa Unjuk Kerja Boiler Terhadap Terhadap Penurunan Daya Pada PLTU. PT. Indonesia Power UBP Perak.

[7] Power Boilers,A Guide to Section I of The ASME Boiler and Pressure Vessel Code by, Martin D,Bernstein,Foster Wheeler Energy Corporation Clinton, New Jersey and Lloyd W.Yoder Wadsorth,Ohio, ASME Press New York 1998.

[8] Materi Pelajaran Kursus Operator Pesawat Uap Kelas 1, Diselenggarakan oleh ,Departemen Tenaga Keraja RI, Kantor Wilayah Propinsi Jawa Barat, Kantor Departemen Kodya/Kabupaten Bogor, Lembaga Pendidikan dan Latihan Industri, CV.Utama.No.2089 A/W9/K3/80/1991.

[9] Ir.Johanes , UPT-LSDE.BPP Teknolog \& PT.KONEBA 18-22 Februari 1991, Pelatihan Konservasi Energi, Perhitungan Efisiensi Boiler.

[10]Ir. Parlindungan Marpaung, Pelatihan Konservasi Energi UPT-LSDE-BPP Teknologi \& PT. KONEBA, 18 - 22 Februari 1991, Konservasi Energi Distribusi UAP.

[11]Ir.MD.Husein, Pelatihan Konservasi Energi UPTLSDE-BPP Teknologi \& PT. KONEBA, 18 - 22 Februari 1991, Manajemen Industri dalam Indsutri.

[12]Ir. Taufik Sastrainata, MSMI, Pelatihan Konservasi Energi UPT-LSDE-BPP Teknologi \& PT. KONEBA, 18 - 22 Februari 1991, Teknik Audit Boiler. 